\title{
NINA PLUTA, LA SOMBRA DEL CRIMEN. DE LA INFLUENCIA DEL GÉNERO CRIMINAL EN LA NARRATIVA HISPANOAMERICANA EN EL CRUCE DE LOS MILENIOS. WYDAWNICTWO NAUKOWE UNIWERSYTETU PEDAGOGICZNEGO, KRAKÓW 2012. PÁGS. 296.
}

\begin{abstract}
Magda Potok, reseña de Nina Pluta: La sombra del crimen. De la influencia del género criminal en la narrativa hispanoamericana en el cruce de los milenios [review of Nina Pluta: La sombra del crimen. De la influencia del género criminal en la narrativa hispanoamericana en el cruce de los milenios], Studia Romanica Posnaniensia, Adam Mickiewicz University Press, Poznań, vol. XL/2: 2013, pp. 160-162. ISBN 978-83-232-2597-3. ISSN 0137-2475. eISSN 2084-4158.
\end{abstract}

En su monografía publicada recientemente (2012) en Cracovia, Nina Pluta invita a analizar el fenómeno de la popularidad del género negro en la narrativa mundial del cruce de milenios. Su interés se centra en los autores latinoamericanos de los últimos treinta años y apunta a la intrigante evolución que ha sufrido la convención criminal, produciendo, aparte de innumerables novelas policíacas y detectivescas al estilo clásico, una variante específica, propia de la posmodernidad, que la autora define como convención dispersa o efecto seudocriminal. La tendencia consiste en reutilizar los elementos constitutivos del género criminal en una narrativa que, en contra o por encima del esquema detectivesco (plantear, investigar y resolver el crimen) dispersa la intriga, desviando su interés hacia otros elementos discursivos, hacia la reflexión filosófica o existencial o directamente hacia la realidad extratextual: social, política y cultural.

El cuestionamiento de la convención (el abandono de la intriga, la falta de determinación del detective, la reflexión metatextual, etc.) hacen patentes las inquietudes de la modernidad tardía, señaladas a nivel discursvo e ideológico: la identidad inestable, la crisis, la fluidez, la duda cognoscitiva y ontológica. En torno a los motivos clásicos —el crimen, la investigación, el detective, la víctima - queda articulada una reflexión sobre las nuevas formas del mal, sobre la insuficiencia de los recursos para reivindicar la justicia, sobre la relatividad del conocimiento, etc.

Los objetivos del volumen son doblemente estimables. Primero porque las narraciones centradas en un cirmen, individual o colectivo (inlcluido el terror estatal), en la literatura de América Latina son tan corrientes que un análisis con afán generalizador debe abarcar un gran número de textos literarios. Asimismo, no es fácil moverse dentro de la misma convención (criminal). Sus multiples mudanzas, subgéneros y variantes exigen un análisis comparatista. La autora ha sabido superar el reto: del abundante corpus textual ha seleccionado las obras más significativas, para este trabajo en particular y para la cultura contemporánea en general. Entre los autores encontraremos a Roberto Bolaño, Alonso Cueto, Martín Kohan, Edmundo Paz-Soldán, Ricardo Piglia, Rodrigo Rey Rosa, Fernando Vallejo, etc. Y a la evolución del género criminal ha dedicado tanta atención que el lector puede sentirse perfectamente instruido.

Para Nina Pluta, la estampa criminal de la narrativa latinoamericana de los últimos decenios está relacionada con los intensos sentimientos de inseguridad, reconocidos y analizados por los grandes pensadores de la filosofía y sociología actual: Ulrich Beck, Alain Badiou, Anthony Giddens o Zygmunt Bauman. A partir de esta perspectiva, la subversión de la intriga criminal - la investigación inconclusa, la fluidez de roles e identidades, la insuficiencia de las herramientas y los conceptos tradicionales para combatir la delincuencia (la razón, la justicia, el orden moral) y el hecho de que el detective no crea en la posibilidad de alcanzar la verdad - se concibe como señal de la conciencia (pos)moderna, marcada por el escepticismo, la renuncia, la ironía y el sentido de absurdo. „La incertidumbre cognoscitiva — afirma la autora - aumenta no sólo en virtud de las influyentes teorías científicas (el principio de incertidumbre) y filosóficas (desde Wittgenstein hasta Derrida), sino también como efecto de la cada vez mayor opacidad de la política" (p. 274). Más adelante comenta Nina 
Pluta que la dispersión de la convención criminal corresponde "al declive de las grandes narraciones rectoras de la modernidad, de la que tanto se ha hablado en estos tiempos" (p. 274). La autora sitúa la problemática fundamental del libro — el análisis de los elementos criminales en la narrativaen el amplio contexto de los estudios sobre la cultura y la sociedad actuales, con referencias a sus críticos más penetrantes (aparte de los pensadores antes mencionados, Nina Pluta alude a los trabajos de Jacques Derrida, Jacques Lacan, Slavoj Žižek, Roland Barthes, Jean Baudrillard, Emmanuel Lévinas, Pierre Bourdieu, Julia Kristeva, y muchos más). Esto es, sin duda alguna, un gran mérito de la monografía, ya que la interpretación de los textos literarios en diálogo con las voces filosóficas más influyentes de la actualidad convierte el libro de Nina Pluta en un trabajo transdisciplinario que cruza los límites de los estudios literarios para integrar la filosofía, la antropología, los estudios culturales y sociológicos.

Aún a pesar de situar su anális en una perspectiva universal y comparatista, la autora hace resaltar la especificidad regional de los textos en cuestión, pues por un lado, la narrativa criminal y seudociminal de América Latina se inscribe en las tendencias globales de la hostilidad, la falta de seguridad, el carácter transitorio ("líquido") de las ideas y de las relaciones, y por otro lado manifiesta una calidad y una condición propias, procedentes de su pasado colonial y de la dramática historia reciente. Según Nina Pluta, el recrudecimiento de los conflictos sociales y políticos en el continente, así como los graves problemas políticos trascendieron a la literatura precismante a través de los recursos de la novela negra.

Entre las características de la narrativa latinoamericana señaladas en el libro destaca el vínculo que ésta mantiene con la realidad social y política. Nina Pluta quiere verlo como una nueva forma de compromiso o un discurso "poscomprometido" (p. 240), que no sirve para apoyar una u otra ideología, sino para censurar los mecanismos políticos, antidemocráticos y amorales, que constituyen una amenaza tanto para los individuos como para la sociedad. En la estela de este planteamiento, Nina Pluta nos hace ver cómo la narrativa hisnpanoamericana actual, valiéndose de la convención criminal, produce un dispositivo crítico apuntado a la delincuencia, el terror y la violencia homicida a la que recurren los gobiernos dictatoriales, como en Argentina o Chile, el narcotráfico, como en México, las formaciones paramilitares, como en Colombia, o las organizaciones terroristas como en Perú.

Tal como se encarna en la ficción, la realidad latinoamericana está marcada por la violencia, en el ámbito político, económico, y en la vida diaria de los ciudadanos. Los robos, los atracos armados, los asesinatos pasan a formar parte de lo cotidiano; el miedo, la miseria y la presencia constante de una amenaza criminal se han convertido en los componentes inseparables de la vida en el continente. A los escritores que convierten esta realidad en la materia de su escritura (Rodrigo Rey Rosa, Fernando Vallejo Antonio Ungar, Guillermo Fadanelli, Horacio Castellanos Moya, Carlos Busqued, Alberto Barrera Tyszka, Yuri Herrera) Nina Pluta los llama "profetas de la antimoral" (p. 200). Estos autores ofrecen "representaciones de unas sociedades roídas por el miedo, que persiste a pesar de la supuesta transición a la democracia" (p. 200). Como consecuencia de ello, se destruyen los valores y colapsan los vínculos sociales, lo cual, según la autora, repercute en la desconfianza generalizada hacia las personas y las instituciones, y lleva a la la caída de la sociedad civil. En su lugar se erigen los "reinos de la anticivilización" (220), "donde nunca cesa la sospecha, la vigilancia y la guerra" (219).

Otro aspecto importante de la narrativa seudocriminal en América Latina señalado por Nina Pluta se halla en el hecho de entrelazar una investigación particular con la búsqueda de de una verdad histórica en el sentido más amplio, nacional o social. Concebir el argumento en forma de una pesquisa permite indagar en el pasado por su propia cuenta con el fin de contrarrestar el ocultamiento de la historia. Con ello, según observa la autora, surge una importante práctica individual de revisión histórica, una especie de "apropiación individual de la historia" (p. 268), que permite fusionar lo político y lo privado en una actitud de independencia frente al fraudulento estado. En 
referencia al Museo de la Revolución de Martin Kohan y Respiración artificial de Ricardo Piglia, la autora comenta que, al cotejar en la narración diferentes tipos de discursos, el privado (diarios, cartas) con el crítico-científico (teorías marxistas, historiografía), ambas novelas toman parte, a su manera ficcional, "en el aún inconcluso debate público de varios países hispanoamericanos sobre las fuentes accesibles en la reconstrucción de la dolorosa historia de los enfrentamientos y el terror" (p. 268).

La literatura desempeña un papel fundamental en el proceso de reconstruir la identidad, personal y social. Nina Pluta explica nítidamente cómo los silencios y las falacias, personales, familiares y políticas, han provocado graves crisis de identidad. En este sentido, lo que proponen estos relatos es utilizar las estrategias (seudo)detectivescas — escuchar a los testigos, estudiar los documentos, investigar y deducir - para recuperar el pasado. Haber destacado este momento de reflexión y reivindicación histórica en el desarrolo de la novela latinoamericana representa otro valor del libro. Nina Pluta interpreta la reciente narrativa de América Latina con el conocimiento experto (y no es fortuito: ella es coautora de la Historia de las literaturas iberoamericanas publicada en Polonia, Ossolineum, en 2010). Sus análisis de los textos frecuentemente conducen a sus fuentes genéricas y aluden a los precursores de los cambios dentro de la convención criminal en America Latina, es decir a Jorge Luis Borges y a Roberto Arlt. El ensayo de Nina Pluta demuestra un profundo entendimiento de la literatura hispanoamericana, la histórica y la actual, a la vez que representa una relevante y original interpretación de la narrativa de los escritores que recurren a la convención criminal para debatir las consecuencias de la violencia, individual y colectiva, así como la relatividad de las categorías constitutivas del género, tales como el conocimiento y la verdad.

Magda Potok

Universidad Adam Mickiewicz de Poznań

\author{
MARZENA CHROBAK, MIĘDZY ŚWIATAMI. TEUMACZ USTNY \\ ORAZ KOMUNIKACJA MIĘDZYKULTUROWA W LITERATURZE ODKRYCIA \\ I KONKWISTY AMERYKI. \\ WYDAWNICTWO UNIWERSYTETU JAGIELLOŃSKIEGO, KRAKÓW 2012. \\ PÁGS. 290.
}

\begin{abstract}
Joanna Studzińska, reseña de Marzena Chrobak: Między światami. Ttumacz ustny oraz komunikacja międzykulturowa w literaturze odkrycia i konkwisty Ameryki [review of Marzena Chrobak: Między światami. Tłumacz ustny oraz komunikacja międzykulturowa w literaturze odkrycia i konkwisty Ameryki], Studia Romanica Posnaniensia, Adam Mickiewicz University Press, Poznań, vol. XL/2: 2013, pp. 162-164. ISBN 978-83-232-2597-3. ISSN 0137-2475. eISSN 2084-4158.
\end{abstract}

Marzena Chrobak, romanista e hispanista de la Universidad Jagellónica de Cracovia, es conocida al público lector polaco sobre todo como traductora de novelas de Mario Vargas Llosa y Eduardo Mendoza. Su nuevo libro, cuyo título puede traducirse Entre mundos: el intérprete y la comunicación intercultural en la literatura del descubrimiento y de la conquista de América, será de enorme interés tanto para traductores e intérpretes, como para historiadores.

Cada una de las tres partes de la monografía investiga el tema principal con relación a otras circustancias geográficas y temporales. La primera parte está dedicada a la región del Mediterráneo, desde los albores de los tiempos hasta los finales del Medievo. Las partes segunda y tercera elaboran 